\title{
Risk of Avalanche Involvement in Winter Backcountry Recreation: The Advantage of Small Groups
}

\author{
Benjamin Zweifel, MSc, PhD; Emily Procter, MSc; Frank Techel, MSc; Giacomo Strapazzon, MD, PhD; \\ Roman Boutellier, Prof \\ From the WSL Institute for Snow and Avalanche Research SLF, Davos, Switzerland (Dr Zweifel and Mr Techel); the EURAC Institute of Mountain \\ Emergency Medicine, Bolzano, Italy (Ms Procter and Dr Strapazzon); the Department of Sport Science, Faculty for Sports Science and Psychology, \\ University of Innsbruck, Innsbruck, Austria (Ms Procter); and the Swiss Federal Institute of Technology, Zurich, Switzerland (Dr Boutellier).
}

\begin{abstract}
Objective.-Avalanches are the primary hazard for winter backcountry recreationists and cause numerous deaths and injuries annually. Although recreationists usually travel in groups, there is little empirical knowledge on group-related risk factors. This study aims to explore the relative risk of avalanche accidents with respect to group size and to discuss underlying reasons for different risk levels.

Methods.-We compared backcountry usage data in regions in Switzerland and Italy with avalanche accident data in these regions.

Results. - We found higher avalanche risk for groups of 4 or more people and lower risk for people traveling alone and in groups of 2 . The relative risk of group size 4, 5, and 6 was higher compared with the reference group size of 2 in the Swiss and Italian dataset. The relative risk for people traveling alone was not significantly different compared with the reference group size of 2 in the Italian dataset but was lower in the Swiss dataset.

Conclusions.- These findings are in accordance with avalanche safety recommendations regarding the higher risk of large groups but not regarding lower risks of people traveling alone in avalanche terrain, which is not recommended and requires great caution. Further studies on backcountry usage are necessary to improve our understanding of human behavior and risk factors. New techniques (eg, video monitoring) may be useful for acquiring reliable data on backcountry usage.
\end{abstract}

Key words: avalanche prevention, backcountry skiing, outdoor recreation, recreational monitoring, avalanche accidents

\section{Introduction}

Recreational activity in avalanche terrain such as backcountry skiing or riding, snowmobiling, or snowshoeing has increased in recent decades due to higher mobility of recreationists and improvements in equipment. The risk of being involved in an avalanche and the associated mortality are high compared with other risks of backcountry recreation such as falls or hypothermia. ${ }^{1,2}$ Based on avalanche accident statistics and user surveys, the majority of recreationists travel in avalanche terrain in groups and only few people travel alone. ${ }^{3,4}$ Group size and the related risk factors play a crucial role in avalanche risk management.

Corresponding author: Benjamin Zweifel, MSc, PhD, WSL Institute for Snow and Avalanche Research SLF, Flüelastrasse 11, 7260 Davos Dorf, Switzerland (e-mail: zweifel@slf.ch).
Characterizing recreation groups by group size has been widely discussed for avalanche risk reduction initiatives. Previous work suggests that the risk of being involved in an avalanche increases with increasing group size. $^{5-8}$ Accordingly, small groups are considered a risk reduction factor in the Risk Reduction Method of Munter, and traveling in small groups and/or keeping distances between single group members are also risk reduction factors in many avalanche decision making tools such as Stop or Go, Snowcard, or Avaluator. ${ }^{9-12}$ Larger groups may have higher risk due to higher load on the snow cover or human factors (eg, decision making or communication). ${ }^{5}$ However, these avalanche safety practices are based on avalanche accident statistics or surveys examining basic demographics, travel behavior, avalanche expertise, or rescue equipment. ${ }^{4,13-18}$ The aim of this study is to estimate the relative risk of avalanche 
accidents with respect to group size by comparing the relative frequency of groups in the field with the relative frequency of accidents in these groups. For the first time, we can estimate relative frequency of groups with data from direct in-field surveys and new social media sources.

\section{Materials and Methods}

To analyze backcountry usage we applied 2 datasets from in-field surveys and 1 dataset from in-field observations. Both methods have been established in recreational monitoring. ${ }^{19}$ Further, social media sources were used as data source. Social media are now frequently used by recreationists to report tours and travel conditions (eg, the mountaineering website bergportal. ch). ${ }^{19}$ We included backcountry skiers and snowshoers and excluded other winter recreationists such as sidecountry skiers or riders (they ascend using mechanized transportation in ski areas, whereas backcountry skiers ascend by their own means), hikers, ice climbers, mountaineers, and snowmobilers. All datasets included group size, date, location, sociodemographics of group members, and activity type.

The ethic committee of the South Tyrolean medical service approved the research protocol.

\section{RECREATION GROUPS IN THE FIELD (USAGE DATA)}

Swiss usage data (self-registration boards, in-field observations, and social network data)

The first usage dataset was collected in a 3-year field campaign (winter 2004-05 to winter 2006-07; each winter from December through April). Voluntary selfregistration boards with survey sheets were installed at Tschuggen in the Flüela valley and at Monstein near Davos, Switzerland, 2 popular starting points for backcountry skiers and snowshoers (Figure 1). ${ }^{20,21}$ A second dataset was collected from observations of 10 avalanche experts from WSL Institute for Snow and Avalanche Research SLF, who counted backcountry skiers and snowshoers in the field between December 2013 and May 2014 while they were on their own backcountry trips. A third usage dataset was taken from the social network website bergportal.ch. We analyzed all entries with known group size from a 5-year period (winter 2010 to winter 2014), as also applied by Techel et al. ${ }^{19}$

\section{Italian usage data (in-field observation)}

In a 1-week field campaign in February 2011 a questionnaire was administered to all skiers and snowshoers departing on a backcountry tour at 22 popular tour

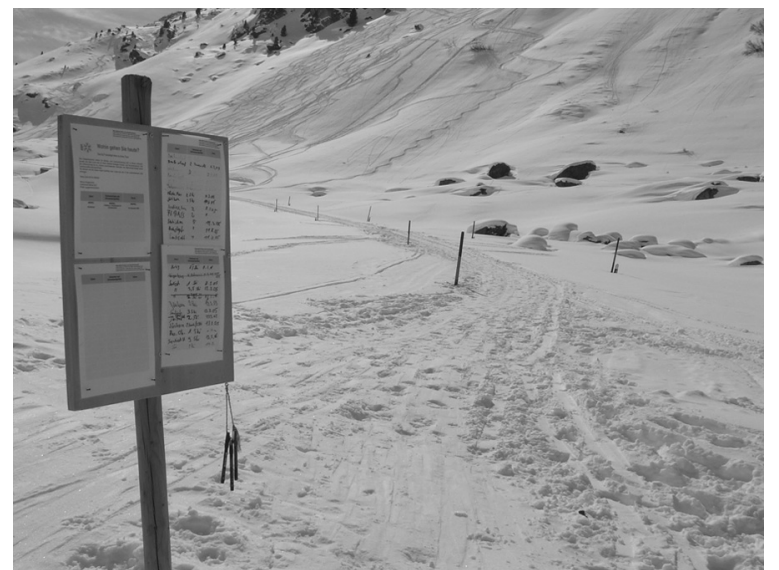

Figure 1. Registration board at Tschuggen in the Flüela Valley, Davos, Switzerland.

starting points in South Tyrol, Italy. ${ }^{3}$ The locations were based on the most frequented locations in a 1-day pilot survey at 143 starting points in $2010 .^{22}$

\section{NATIONAL ACCIDENT DATABASES (ACCIDENT DATA)}

In order to have representative datasets, accident data were collected over a 10-year period and not only the period of the usage datasets. However, the usage data stems from a period covered by the accident datasets.

\section{Swiss avalanche database}

The Swiss avalanche database contains all recorded avalanches in Switzerland that produced a material or economic damage or damage to persons. Data are reported from rescue organizations, mountain guides, SLF observers, or backcountry recreationists. We extracted accidents with single groups involving backcountry skiers and snowshoers in a 10-year period (winter 2003-04 to winter 2012-13).

\section{Italian avalanche database}

The Italian avalanche database contains all recorded avalanches in Italy. Data were collected by the regional avalanche warning services and sent to a central database that is managed by an association (Associazone Interregionale Neve e Valanghe, AINEVA). We included all avalanche accidents involving backcountry skiers and snowshoers in a 10-year period (winter 2004-05 to winter 2013-14) in South Tyrol, Italy.

\section{DATA ANALYSIS}

Avalanche risk is defined as the ratio of the total number of accidents to the total number of exposed individuals. 
Relative risk refers to the ratio of avalanche risk in the 2 groups being compared. There are currently no available datasets that contain both the number of exposed individuals and the number of accidents for the same individuals; thus we assessed relative risk by comparing group size distributions in the usage data with group size distributions in the accident data for both countries. It was assumed that if the usage data is a representative sample of backcountry recreationists and that group size has no influence on avalanche risk, the usage and accident datasets should have the same group size distribution. Group sizes were analyzed by comparing 6 group size classes: groups consisting of 1, 2, 3, 4, 5, and $\geq 6$ people. Large groups were combined in 1 class because 1) the Bergportal data did not contain exact group sizes for larger groups, and 2) the absolute number of large groups was low (maximal 10\% for usage datasets and maximal $23 \%$ for accident datasets; see the Table). In a first step we compared group size distribution between the different usage datasets by applying the nonparametric Wilcoxon rank sum test. ${ }^{23}$ In a second step we compared the group size distribution of usage data with accident data for Swiss and Italian datasets and calculated the relative risk for a specific group size $i$ with respect to the most frequent group size (reference group: group size 2) as $R R_{i}=\frac{a^{a c c_{i}} \text { usage }_{\text {ref }}}{\text { acc }_{\text {ref }} \text { usage }_{i}}$, as it can be shown that the relative risk

$$
\begin{aligned}
R R & =\frac{R_{i}}{R_{\text {ref }}}=\frac{\text { acc }_{i}}{\text { exposed }_{i}} \frac{\text { exposed }_{\text {ref }}}{\text { acc }_{\text {ref }}} \\
& =\frac{\text { acc }_{i}}{\text { acc }_{\text {ref }}} \frac{p_{\text {ref }} \text { exposed }_{p_{i} \text { exposed }}=\frac{\text { acc }_{i}}{\text { acc }_{\text {ref }}}}{\frac{\text { usage }_{\text {ref }} / \text { usage }}{\text { usage }} \text { / usage }},
\end{aligned}
$$

where $R$ is the risk, acc the frequency of accidents, exposed the number of exposed persons, $p$ the relative frequency of group size, and usage is the frequency of persons; $i$ refers to a specific group size, ref to the reference group size (2), and no subscript to the total. $R R$ $=1$ means that the risk of being involved in an accident in the investigated group is similar to the reference group, $R R>1$ indicates that the risk is higher, and $R R$ $<1$ indicates that the risk is lower with respect to the reference group. The $R R$ was considered significant if the Pearson $\chi^{2}$ test $^{24}$ showed a $P<.05$.

\section{Results}

\section{GROUP SIZE DISTRIBUTIONS IN USAGE AND ACCIDENT DATASETS}

An overview of the datasets including median group size and group size distribution are shown in the Table and Figure 2. The median group size for usage datasets was 2 for all datasets; median group size in both accident datasets was 3 . Group size 2 was the most frequent in all datasets (22\%-44\%). The frequency of group size 1 and 3 was similar (8\%-26\%) and frequency decreased with increasing group size.

In the dataset from the Davos self-registration boards we found higher frequency in usage compared with accidents in group size 1 (17\% usage vs $8 \%$ accidents) and 2 (44\% usage vs 35\% accidents). Frequencies of usage and accidents were similar for group size 3 (15\% usage vs $16 \%$ accidents) and 4 (10\% usage vs $11 \%$ accidents). Frequency of usage was lower than accidents for group size 5 (4\% usage vs $7 \%$ accidents) and 6 or more people (10\% usage vs $23 \%$ accidents) (Table, Figure 2).

In the dataset from the Davos in-field observations we found higher frequency in usage compared with accidents in group size 1 ( $27 \%$ usage vs $8 \%$ accidents) and 2 ( $41 \%$ usage vs $35 \%$ accidents). Frequencies of usage and accidents were similar for group size 3 (18\% usage vs $16 \%$ accidents). Frequency of usage was lower than accidents for group size 4 (5\% usage vs $11 \%$ accidents), 5 ( $2 \%$ usage vs $7 \%$ accidents), and 6 or more people ( $7 \%$ usage vs $23 \%$ accidents) (Table, Figure 2).

\begin{tabular}{|c|c|c|c|c|c|c|c|c|c|}
\hline \multirow[b]{2}{*}{ Data type } & \multirow[b]{2}{*}{ Dataset } & \multirow[b]{2}{*}{$N$} & \multirow[b]{2}{*}{ Median group size $(n)$} & \multicolumn{6}{|c|}{ Group size distribution (\%) } \\
\hline & & & & 1 & 2 & 3 & 4 & 5 & $\geq 6$ \\
\hline \multirow[t]{4}{*}{ Usage } & $\mathrm{CH}$ - Davos (self-registration boards) & 2299 & 2 & 17 & 44 & 15 & 10 & 4 & 10 \\
\hline & $\mathrm{CH}$ - Davos (in-field observation) & 238 & 2 & 27 & 41 & 18 & 5 & 2 & 7 \\
\hline & $\mathrm{CH}$ - Bergportal & 10310 & 2 & 26 & 39 & 15 & 7 & 4 & 9 \\
\hline & IT - South Tyrol & 1927 & 2 & 22 & 42 & 15 & 8 & 5 & 8 \\
\hline \multirow[t]{2}{*}{ Accident } & Swiss national database & 446 & 3 & 8 & 35 & 16 & 11 & 7 & 23 \\
\hline & Italian national database & 91 & 3 & 18 & 22 & 18 & 16 & 9 & 18 \\
\hline
\end{tabular}

Table. Overview of usage and accident datasets

$\mathrm{CH}$, Switzerland; IT, Italy. 

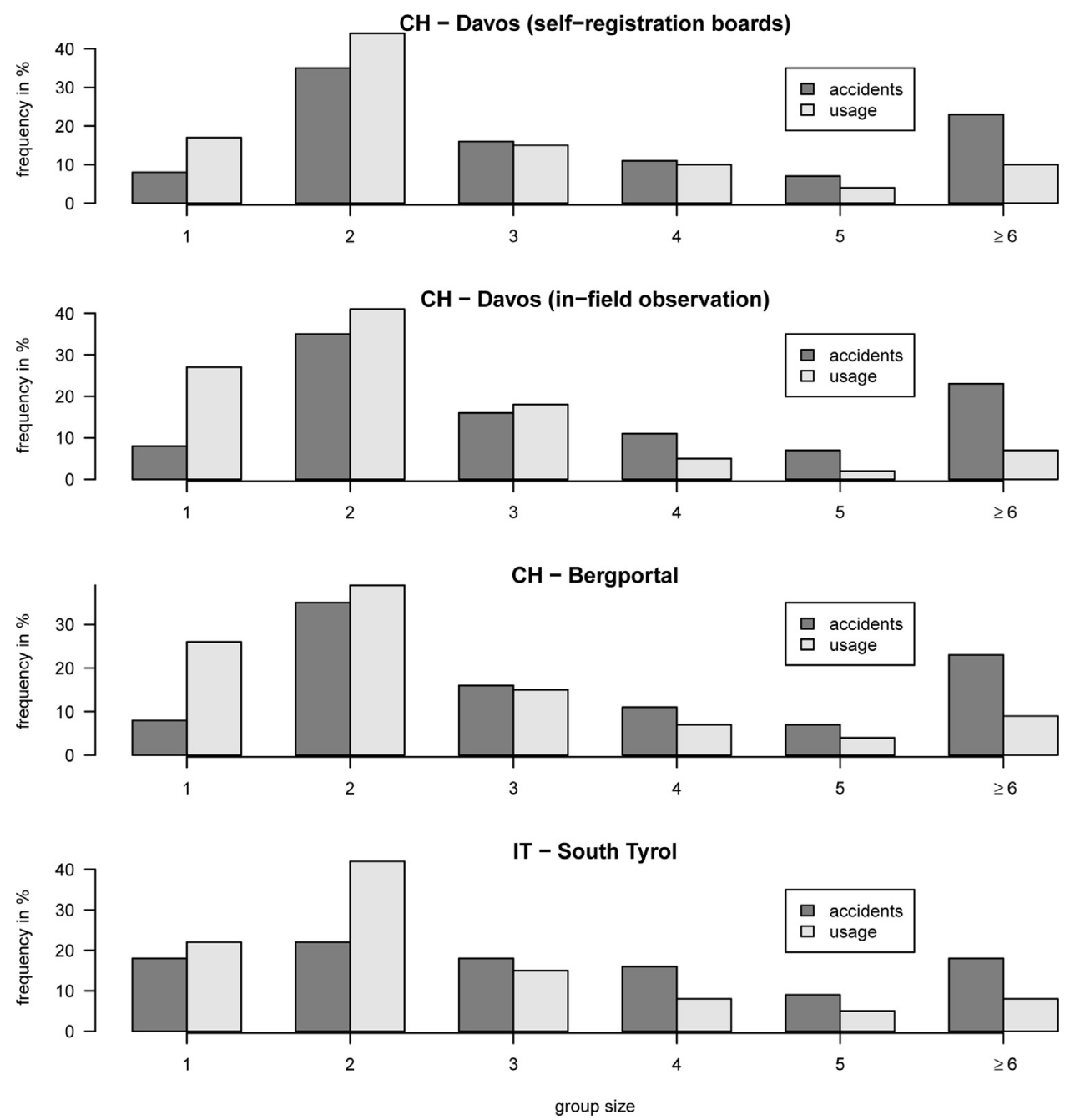

Figure 2. Distribution of group sizes from the 3 Swiss usage datasets compared with the Swiss accident data (top three) as well as the Italian usage dataset compared with the Italian accident data (bottom).

In the dataset from bergportal.ch we found higher frequency in usage compared with accidents in group size 1 (26\% usage vs $8 \%$ accidents) and 2 (39\% usage vs $35 \%$ accidents). Frequencies of usage and accidents were similar for group size 3 (15\% usage vs $16 \%$ accidents). Frequency of usage was lower than accidents for group size 4 ( $7 \%$ usage vs $11 \%$ accidents), 5 (4\% usage vs $7 \%$ accidents), and 6 or more people (9\% usage vs $23 \%$ accidents) (Table, Figure 2).

In the Italian datasets we found higher frequency in usage compared with accidents in group size $1(22 \%$ usage vs $18 \%$ accidents) and 2 (43\% usage vs $22 \%$ accidents). Frequency of usage was lower than accidents for group size 3 (15\% usage vs 18\% accidents), 4 ( $8 \%$ usage vs $16 \%$ accidents), 5 (5\% usage vs $9 \%$ accidents), and 6 or more people ( $8 \%$ usage vs $18 \%$ accidents) (Table, Figure 2).
We found no difference in group size distribution between usage data from the in-field observations in Davos and the bergportal.ch usage data $(P=.220)$. However, the group size distribution from the selfregistration boards in Davos differed from the Davos in-field observations $(P<.001)$ and from the bergportal. ch usage data $(P<.001)$; the Davos self-registration board usage dataset showed relatively fewer people traveling alone. Group size distribution was different in each of the 3 Swiss usage datasets compared to the Swiss avalanche accidents $(P<.001$ for all $)$ showing relatively more people traveling alone in the usage datasets compared with the accident dataset and relatively fewer people in groups of 6 or more in the usage datasets compared with the accident dataset. The Italian usage dataset differed in group size distribution compared with the Italian avalanche accidents $(P<.001)$, whereby the 
usage dataset showed relatively more people in groups of 2 and relatively fewer people in groups of 6 or more compared with the accident dataset. No differences in group size distribution were found between the Swiss and Italian accident datasets $(P=.584)$ (Table, Figure 2).

\section{RELATIVE RISK OF AVALANCHE INVOLVEMENT}

Relative risk (RR) for all group sizes in the Swiss and Italian datasets is shown in Figure 3. In the Davos selfregistration boards dataset group size 1 had an RR of 0.56 (95\% confidence interval [CI] $0.38-0.82$ ), which indicates significantly lower avalanche risk than the reference group size $2(P=.003)$. Groups size 3 had an RR of 1.32 (CI $0.97-1.79 ; P=.070$ ), and group size 4 had an RR of 1.30 (CI $0.90-1.84 ; P=.153$ ), which was not higher for either of these groups compared with group size 2 . Group size $5(\mathrm{RR}=2.40 ; 95 \% \mathrm{CI}$
1.54-3.68; $P<.001)$ and 6 or more people $(\mathrm{RR}=$ 2.14; CI $1.30-3.43 ; P=.002$ ) had significantly higher RR than the group size 2 .

In the dataset from the Davos in-field observation group size 1 had an RR of 0.33 (CI $0.20-0.54$ ), which was significantly lower than the avalanche risk from the reference group size $2(P<.001)$. Group size 3 had an RR of 1.08 (CI 0.69-1.72), which was not significantly higher than group size $2(P=.726)$. Group size $4(\mathrm{RR}=$ 2.23; CI $1.18-4.52 ; P=.014), 5(\mathrm{RR}=4.96 ; \mathrm{CI}$ $1.89-17.45 ; P<.001)$, and 6 or more people $(\mathrm{RR}=$ 7.27; CI $2.09-49.60 ; P=.001)$ had significantly higher RR than the group size 2 .

In the dataset from the bergportal.ch group size 1 had an RR of 0.33 (CI $0.22-0.47$ ), which was significantly lower than RR from the reference group size $2(P<$ .001 ). Group size 3 had an RR of 1.22 (CI 0.91-1.62), which was not significantly higher than group size 2 $(P=.168)$. Group size $4(\mathrm{RR}=1.60 ; \mathrm{CI} 1.13-2.22$; $P=.006), 5(\mathrm{RR}=2.24$; CI $1.50-3.27 ; P<.001)$, and
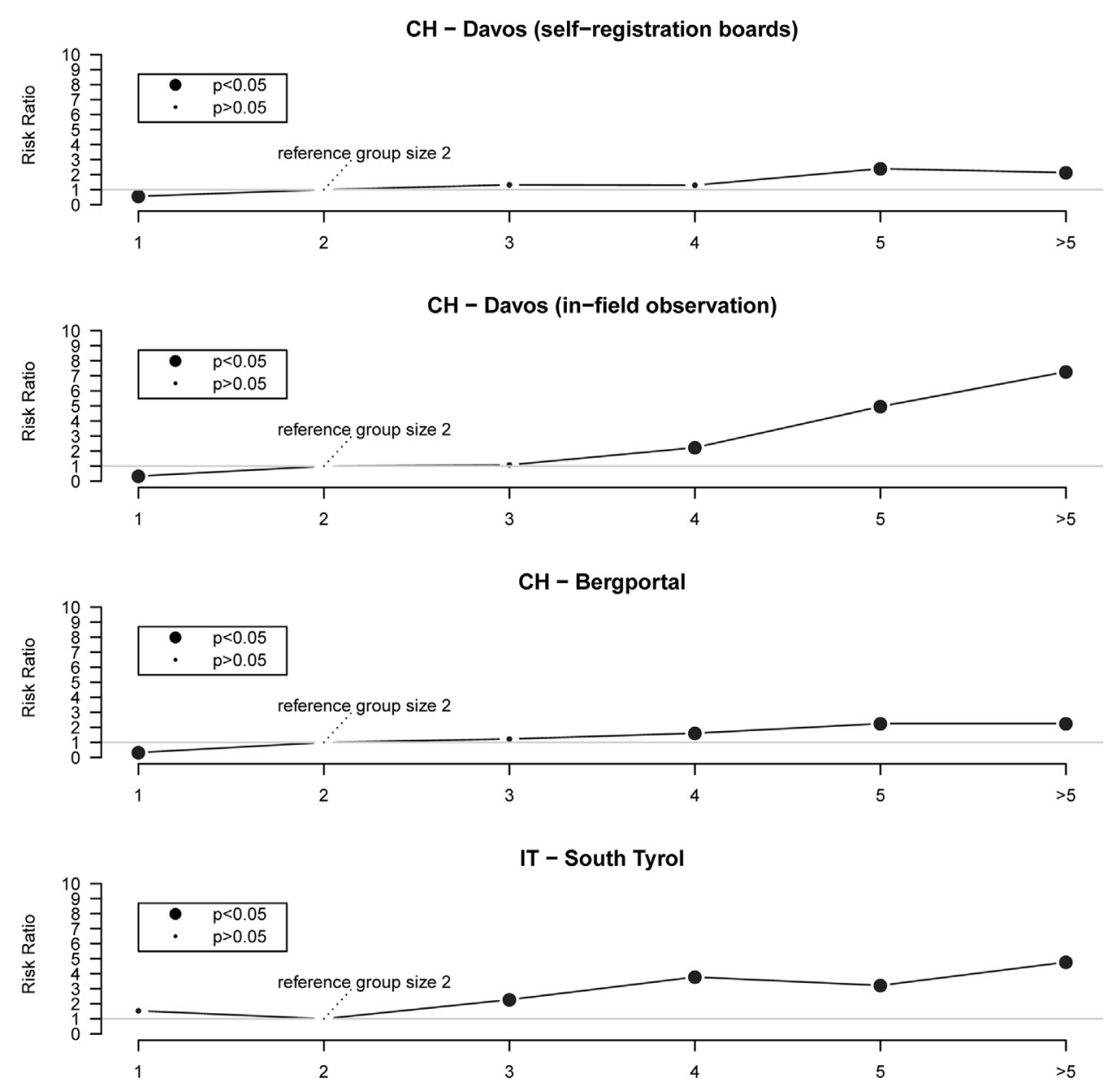

Figure 3. Relative risk of group size 1, 3, 4, 5, and 6 or more compared with the reference group (size 2) in the 3 Swiss usage datasets and for the Italian dataset. The size of the bullet points indicates the significance level. 
6 or more people $(\mathrm{RR}=2.68$; CI 2.06-3.47; $P<.001)$ had significantly higher RR than the group size 2 .

In the Italian datasets group size 1 had an RR of 1.53 (CI 0.77-3.00), which was not significantly higher than the reference group size $2(P=.208)$. Group size 3 (RR $=2.27$; CI $1.14-4.46 ; P=.014), 4(\mathrm{RR}=3.78 ; \mathrm{CI}$ 1.86-7.55; $P<.001), 5(\mathrm{RR}=3.22$; CI 1.29-7.30; $P$ $=.005)$, and 6 or more people $(\mathrm{RR}=4.77$; CI $1.50-12.57 ; P=.001$ ) had significantly higher avalanche risk than group size 2 .

\section{Discussion}

We calculated the relative risk of avalanche involvement with respect to group size for the first time by comparing accident data with data from in-field usage. The results suggest lower avalanche risk for people traveling alone or in groups of 2, and higher risk for groups of 4 or more people. The highest risk was found for groups of 6 or more people in both the Swiss and Italian datasets.

Our findings are in agreement with avalanche safety literature, which emphasizes increasing risk with increasing group size. ${ }^{5-8}$ Harvey et al referred to 5 causes of increasing risk in large groups: 1) higher load on the snow cover, 2) increased probability to hit a weak spot in the snow cover, 3) slower decision making process of groups, 4) challenges in communication, and 5) high-risk appetite due to an increased but wrong sense of security (related to the risky shift effect [J.A.F. Stoner, unpublished data, 1961]). ${ }^{5}$ These factors are absent when someone travels alone in avalanche terrain, which may explain why we did not find higher risk in group size 1. However, these results should be considered with caution and do not replace avalanche safety recommendations, which strongly deter recreationists from traveling alone because of the potential consequences of being involved in an accident alone as well as the risk of injuries, fatigue, or getting lost. ${ }^{25}$ Companion rescue is imperative for rapid extrication of buried avalanche victims, and survival probability is high if the victim is extricated within 18 minutes of burial. $^{26,27}$ Nearly one quarter of all recreationists in these datasets were traveling alone. But we should not forget that rapid help is a reaction after an accident has happened whereas the choice of a small group size is a preventive measure.

Although the above risk factors may be obvious for large groups these statements are also controversial. Group decision-making is a highly complex topic and there is no empirical evidence whether groups make better decisions than individuals or if group decisionmaking pitfalls prevail. ${ }^{28-31}$ Communication research has shown that communication quality decreases when group size increases, and some research found evidence for an increasing risky shift effect with increasing group size. ${ }^{32-36}$ However, a better understanding of behavior and processes within recreational groups traveling in avalanche terrain is necessary to determine which risk factors are common in larger groups.

Our findings are valuable for understanding avalanche safety related to group size with specific implications: 1) the finding that group size 2 was the most common in accidents has been interpreted as higher risk in group size 2 , but considering the relative frequency of users we found lower risk than for larger groups. ${ }^{13,14}$ 2) Our findings support the hypothesis of increased avalanche risk for large groups and we encourage avalanche educators to stress risk reduction measures for large groups, such as effective measures for safe guiding, open group communication, or appropriate group organization. 3) The avalanche safety community should discuss how to advise recreationists who travel alone because data suggest that many people do travel alone despite the potential consequences; it is also unclear how avoiding some of the pitfalls of group dynamics and decisionmaking may affect risk for solo travelers. 4) Guided groups are often large and guides should discuss strategies to reduce risk. Finally, 5) our findings show similarities in group size distribution and risk across group sizes between these 2 regions, but further research may investigate country-specific similarities and differences in more detail.

\section{Limitations}

One limitation of this study is that usage data may not be representative of the total number of recreationists active in a geographic region or during an average winter season. However, obtaining usage data will always be a logistical challenge and to the authors' knowledge this is the first attempt to use data from in-field surveys wherever possible, which remains the most direct means of estimating the number of recreationists. Another limitation is that the analysis is limited to only those parameters that are comparable between datasets. Group size was defined and collected in the same way in all datasets. Other parameters such as gender, age, or leadership were not consistently available in all datasets, which prevented additional comparisons. Finally, accident datasets are also prone to reporting bias; for example, accidents without serious consequences are underreported. It has been estimated from Swiss data that $20 \%$ of avalanche involvements remain unknown. ${ }^{37}$ However, the accident data included in this study were taken from national databases, and all reported accidents 
with known group size were included for the specified period.

\section{Conclusion}

For the first time, we quantitatively investigated the effect of group size on avalanche risk by comparing the relative frequency of groups in the field with the relative frequency of accidents in these groups. The results support previous hypotheses that avalanche risk is higher in larger groups. ${ }^{6}$ Groups of 2 are the most common and had lower relative risk of avalanches than larger groups, which contrasts previous statements about risk that are based on frequency of accidents in avalanche accident statistics. Although recreationists who travel alone did not have higher risk than groups, this result is not conclusive and does not replace current avalanche safety recommendations. To overcome the current limitations of risk analyses (ie, methodical challenges and incomplete data), we recommend that avalanche safety organizations encourage data collection of backcountry recreationists. Video monitoring may be a promising technique in outdoor recreation. ${ }^{20,38}$ Future research could integrate other factors into the risk analysis such as gender, age, travel behavior, or level of expertise. This would improve our understanding of human factors and avalanche risk and help refine avalanche safety recommendations.

\section{Acknowledgments}

We thank Reto Baur from Bergportal $\mathrm{GmbH}$ for the permission to use their data. We also thank Markus Falk (EURAC Institute of Mountain Emergency Medicine, Bolzano, Italy) who provided valuable input on the methodical approach and contributed to the quality of the manuscript. We further thank the organizations who reported and collected accident data in Switzerland (REGA, Air Glacier, Air Zermatt, SLF observers, avalanche rescuers, and backcountry recreationists) and the organizations who did the in-field surveys and provided accident data in South Tyrol (mountain rescue organizations, the Department of Fire and Civil Protection, and Avalanche Warning Services).

\section{References}

1. McIntosh SE, Grissom CK, Olivares CR, Kim HS, Tremper B. Cause of death in avalanche fatalities. Wilderness Environ Med. Winter. 2007;18:293-297.

2. Silverton NA, McIntosh SE, Kim HS. Risk assessment in winter backcountry travel. Wilderness Environ Med. 2009; 20:269-274.
3. Procter E, Strapazzon G, Dal Cappello T, Castlunger L, Staffler HP, Brugger H. Adherence of backcountry winter recreationists to avalanche prevention and safety practices in northern Italy. Scand J Med Sci Sports. 2014;24:823-829.

4. Zweifel B, Techel F, Björk C. Who is involved in avalanche accidents? International Snow Science Workshop 2012 Proceedings. September 16-21, 2012; Anchorage, AK; 2012:234-239.

5. Harvey S, Rhyner H, Schweizer J. Lawinenkunde. München, Germany: Bruckmann Verlag GmbH; 2012.

6. McClung D, Schaerer P. The Avalanche Handbook. 3rd ed. Seattle, WA: Mountainers Books; 2006.

7. Tremper B. Staying Alive in Avalanche Terrain. 2nd ed. Seattle, WA: Mountainers Books; 2008.

8. Volken M, Schell S, Wheeler M. Backcountry Skiing: Skills for Ski Touring and Ski Mountaineering. 3rd ed. Seattle, WA: Mountainers Books; 2007.

9. Munter W. Neue Lawinenkunde: Ein Leitfaden für Die Praxis Bern, Switzerland: SAC; 1992.

10. Larcher M. Stop or Go: Entscheidungsstrategie für Tourengeher. Berg \& Steigen - Zeitschrift für Risikomanagement im Bergsport. Oesterreichischer Alpenverein, Innsbruck, Austria; 1999;8(4):18-23.

11. Engler M, Mersch J. SnowCard: Lawinen - Risiko - Check. Sulzberg, Germany: Verlag Martin Engler; 2000.

12. Haegeli P, McCammon I. Avaluator Avalanche Accident Prevention Card. Revelstoke, BC: Canadian Avalanche Centre; 2006.

13. Atkins D. Human factors in avalanche accidents. International Snow Science Workshop 2000 Proceedings. Big Sky, MT; 2001:46-51.

14. McCammon I. Evidence of heuristic traps in recreational avalanche accidents. In: Stevens JR, ed. International Snow Science Workshop 2002 Proceedings. Penticton, BC; 2002:244-251.

15. Gunn M. Out of Bounds Skiers and Avalanche Risk: High-Risk Cohort Identification and Characterization. M.R.M. research project no. 604, 2014-3. Burnaby, BC: School of Resource and Environmental Management Simon Fraser University; 2010.

16. Haegeli P, Gunn M, Haider W. Identifying a high-risk cohort in a complex and dynamic risk environment: Outof-bounds skiing-An example from avalanche safety. Prev Sci. 2012;13:562-573.

17. Sole A. Human Risk Factors in Avalanche Incidents [Master's thesis]. Calgary, AB: University of Calgary; 2008.

18. Tase JE. Influences on Backcountry Recreationists' Risk of Exposure to Snow Avalanche Hazard [Master's thesis]. Bozeman, MT: University of Montana; 2004.

19. Techel F, Zweifel B, Winkler K. Avalanche risk in backcountry terrain based on usage frequency and accident data. Nat Hazard Earth Sys. 2014;2:5113-5138.

20. Cessford G, Muhar A. Monitoring options for visitor numbers in national parks and natural areas. $J$ Nat Conserv. 2003;11:240-250.

21. Zweifel B, Raez A, Stucki T. Avalanche risk for recreationists in backcountry and in off-piste area: surveying methods and pilot study at Davos, Switzerland. In: 
Gleason JA, ed. International Snow Science Workshop 2006 Proceedings. Telluride, CO; 2006:733-741.

22. Brugger H, Staffler HP, Aberer A, Castlunger L, Strapazzon G. Vollerhebung Schitourengeher in Südtirol. Bergundsteigen Zeitschrift für Risikomanagement im Bergsport. Oesterreichischer Alpenverein, Innsbruck, Austria. 2010;19:58-61.

23. Crawley M. The R book. 1st ed. West Sussex, England: John Wiley and Sons Ltd; 2007.

24. Boslaugh S, Watters P. Statistics in a Nutshell: A Desktop Quick Reference. Sebastopol, CA: O’Reilly Media Inc; 2008.

25. Ferguson SA, LaChapelle ER. The ABCs of Avalanche Safety. 3rd ed. Seattle, WA: Mountaineers Books; 2003.

26. Brugger H, Durrer B, Adler-Kastner L, Falk M, Tschirky F. Field management of avalanche victims. Resuscitation. 2001;51:7-15.

27. Mair P, Frimmel C, Vergeiner G, et al. Emergency medical helicopter operations for avalanche accidents. Resuscitation. 2013;84:492-495.

28. Stasser G, Dietz-Uhler B. Collective choice, judgement and problem solving. In: Hogg MA, Tindale S, eds. Blackwell Handbook of Social Psychology: Group Processes. Malden, MA: Blackwell; 2001:31-35.

29. Bright LS. Group Dynamics and Decision Making: Backcountry Recreationists in Avalanche Terrain [dissertation]. Fort Collins, CO: School of Education, Colorado State University; 2010.

30. Kerr NL, MacCoun RJ, Kramer GP. Bias in judgment: comparing individuals and groups. Psychol Rev. 1996;103: $687-719$.

31. Stasser G, Titus W. Pooling of unshared information in group decision making: giased information sampling during discussion. J Pers Soc Psychol. 1985;48:14671478.

32. Burgoon JK, Bonito JA, Ramirez A, Dunbar NE, Kam K, Fischer J. Testing the interactivity principle: effects of mediation, propinquity, and verbal and nonverbal modalities in interpersonal interaction. J Commun. 2002;52: 657-677.

33. Dunbar RIM. Grooming, Gossip, and the Evolution of Language. Cambridge, MA: Harvard University Press; 1996.

34. Lowry PB, Roberts TL, Romano NC, Cheney PD, Hightower RT. The impact of group size and social presence on small-group communication: does computer-mediated communication make a difference? Small Gr Res. 2006;37:631-661.

35. Barnir A. Can group- and issue-related factors predict choice shift? A meta-analysis of group decisions on life dilemmas. Small Gr Res. 1998;29:308-338.

36. Teger AI, Pruitt DG. Components of group risk taking. J Exp Soc Psychol. 1967;3:189-205.

37. Techel F, Zweifel B. Recreational avalanche accidents in Switzerland: trends and patterns with an emphasis on burial, rescue methods and avalanche danger. In: Naaim-Bouvet F, Durand Y, Lambert R, eds. International Snow Science Workshop 2013 Proceedings. Grenoble, France: ANENA, IRSTEA, Météo-France; 2013: 1106-1112.

38. Arnberger A, Haider W, Brandenburg C. Evaluating visitor-monitoring techniques: a comparison of counting and video observation data. Environ Manage. 2005; 36:317-327. 